\title{
Mind mapping tool increased critical thinking through blended learning
}

\author{
Yunike Juniarti Fitria', Tri Wahyuni Floriasti ${ }^{2}$, Djohan³, Phakkharawat Sittiprapaporn ${ }^{4}$ \\ Lecturer, Departments of ${ }^{1}$ Music Education, ${ }^{2}$ English Education, Yogyakarta State University, ${ }^{3}$ Professor, Graduate \\ School of Indonesia Institute of the Arts Yogyakarta, Yogyakarta, Indonesia, ${ }^{4}$ Assistant Professor and Head, Brain \\ Science and Engineering Innovation Research Group, School of Anti-Aging and Regenerative Medicine, Mae Fah \\ Luang University, Bangkok, Thailand, and Department of Anti-Aging Science, School of Anti-Aging and Regenerative \\ Medicine, Mae Fah Luang University, Bangkok, Thailand
}

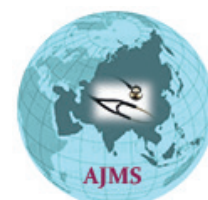

A B S T R A C T

Background: The process of learning creates interaction and coordination and finding solution. Students who are engaged in that process will find themselves useful as they have shared ideas. Sharing ideas is a significant part. Aims and Objective: This study aims to describe the application of mind mapping in music learning as an effort to increase students' critical thinking. It has not been commonly applied in practical music learning processes. Materials and Methods: This research was conducted with a total of 75 students of music education who took violin subject. Initially, they discussed the issue that related with a song, and it was followed by mind mapping to find the ideas. Results: Through this process, students are expected to get a comprehensive understanding, and obtain effectively relevant guidelines regarding the material that must be trained. Conclusion: Exceedingly students can generate critical thinking, which later give influence in song interpretation.

\section{Access this article online}

Website:

http://nepjol.info/index.php/AJMS DOI: 10.3126/ajms.v11i1.26516 E-ISSN: 2091-0576 P-ISSN: $2467-9100$

Key words: Mind mapping; Critical thinking; Music learning; Blended learning

\section{INTRODUCTION}

In the education community, understanding the brain can help open new pathways to improve educational research, policy, and practice. Due to the educational process goes significantly with developments and changes in the brain that are continually changing throughout human life. Besides that, there is an argument which states that the most important insight for education from the field of neuroscience is that the brain is highly adaptive, a property called plasticity. ${ }^{1-3}$ Plasticity is the brain's response to environmental demands. As Karen Evans said that learning is always related to social contexts and is an interaction between learners and their environment. For a long time, it is assumed that the primary brain development occurs in childhood. Today, this belief has clearly changed. It is now evident that the brain undergoes significant changes throughout life. ${ }^{3}$ This is very interesting and becomes a good hope if it is linked in the context of higher education learning. The fact that the human brain continues to change and develop throughout life and it is greatly influenced by how it interacts with the environment. Then the brain's work will be more optimal if it is formed an environment that can support the learning process.

The process of learning creates interaction and coordination and finding solution. Students who are engaged in that process will find themselves useful as they have shared ideas. ${ }^{4} \mathrm{He}$ is the one who enlighten the teaching and leadership method in Indonesia education. He explained that students are given the flexibility to express their idea, feeling and creativity. Moreover, his method was named "among" which is defined as assisting, encouraging patiently. The relation between lecturer and students, students and students are warm to promote their creativity, initiative and desire to think and learn. Moreover, learning should see the local culture where it is applied. Next, he also explains the important of environment and culture. By comprehending these factors, both lecturer and students 
will reach the agreement how they should learn and how to deal with new things, difference, and conflicts as they understand the values of culture and environment. For example, Indonesia consists of 17.506 islands, 746 languages, and 1.128 tribes. It can be said that Indonesia is multicultural country, which enrich the national heritage and strengthen the identity of Indonesian as well. The uniqueness of Indonesia is priceless treasures that unite people in diversity. However, the diversity itself may trigger potential conflict among Indonesian or between Indonesian and foreigners. Knowing, learning, comprehending and applying the knowledge of culture in daily life will glue them and avoid the future conflict. Therefore, giving cultural knowledge to students is one practical way to enlighten them how to appreciate differences then go hand in hand with others in Indonesia and in the world. Securing this knowledge is a process to develop good characters such as appreciative, democratic, and tolerant. ${ }^{5}$ In the learning process, any student deals with new things that give them information and knowledge from others. As a response there will intense communication and discussion. The process of getting the knowledge can be from the lecturer, friends, and e-learning or maybe blended learning as students live in industry revolution $4.0 .^{6}$

Blended learning was applied for this subject. It is a combination between face to face interaction and e-learning. It was designed to meet the students learning needs. Their learning needs were gathered by a set of questionnaires of needs analysis. In the procedure questions, blended learning was offered which were focus on mind mapping. Thus, students got a chance to attend and participate in blended learning. Some of them may start learning from the very basic level hierarchical of Bloom taxonomy which is remembering what, when and who of new knowledge. Once students understand the knowledge, they will go up to the upper level of it. When designing and examining learning strategies to promote critical thinking, educators often use Bloom's Taxonomy as a framework for instruction and assessment. ${ }^{7}$

In the teaching learning process, student's way of thinking from the basic level and early step in thinking, before ending up in critical thinking. The higher they reach the hierarchy the higher the level of thinking skills. To get the higher ones, students learn from many sources and media, one of them is mind map which is designed to help them reaching the critical one.Following the Bloom taxonomy, the approach of teaching from the Among approach by supporting the process of reaching the critical thinking as students were given the situation which trigger their innovation, ideas, and evaluating information and knowledge, then creating something. As it promotes humanistic situation in teaching learning process. The teaching learning process provides students with cognitive skills such as understanding, arguing, negotiating, exploring, deciding, evaluating. All of them is in valued learning situation which trigger student's empathy, tolerance, and prudence. Critically, and deciding to accept or refuse information. This critical character is just a starting point of other magnificent characters, such as innovative, creative and accountable which are go side by side in developing outstanding characters. Therefore, the aims of teaching learning process through mind map is can be reached.

Critical thinking can be defined as the way someone's learn, identify, and processing any information before deciding the solution and creating things. Critical thinking is a conscious and deliberate process used to interpret or evaluate information and experiences with a set of reflective attitudes and abilities that guide thoughtful beliefs and actions. ${ }^{8}$ Similarly, it defined as a reasonable reflective thinking focused on deciding what to believe or do. In reasonably and reflectively going about deciding what to believe or do, a person characteristically needs to independently judge the credibility of sources, identify conclusions, reasons, and assumptions, judge the quality of an argument, including the acceptability of its reasons, assumptions, and evidence., develop and defend a position on an issue, ask appropriate clarifying questions, plan experiments and judge experimental designs, define terms in a way appropriate for the context, be open-minded, try to be well informed, and draw conclusions when warranted, but with caution. ${ }^{9}$

According to Chance, ${ }^{10}$ critical thinking is the ability to analyse facts, generate and organize ideas, defend opinions, make comparisons, draw inferences, evaluate arguments and solve problems. Meanwhile, Robert J. Sternberg ${ }^{11}$ stated that critical thinking comprises the mental processes, strategies, and representations people use to solve problems, make decisions, and learn new concepts. Thus, critical thinking can be also seen as the combination of well-prepared way of thinking which means cognitive part and maturity of mental condition as the process involved decision making. However, an important distinction was made by Paul. ${ }^{12}$ This distinction is between critical thinking as simply rationalizing and defending a position or existing bias in an 'atomistic and sophistic' manner (weak sense), compared with a 'global and Socratic' challenging (strong sense) of previously held assumptions and an identification of contradictions in personal and social life.

There are two very different conceptions depending on how broadly or narrowly critical thinking is viewed. In the weak sense, critical thinking is a set of discrete micro-logical skills concerned with technical reasons, while in the strong sense it is a set of integrated macro-logical skills concerned 
with insight and the development of emancipatory reason. It is the holistic and Socratic sense of critical thinking that is of concern in an educational setting. Those who see critical thinking in a holistic manner suggest there are a number of phases ${ }^{13}$, that include (1) suggestions, in which the mind leaps forward to a possible solution, (2) an intellectualization of the difficulty or perplexity that has been felt (directly experienced) into a problem to be solved, a question for which the answer must be sought, (3) the use of one suggestion after another as a leading idea, or hypothesis, to initiate and guide observation and other operations in collection of factual material, (4) the mental elaboration of the idea or supposition (reasoning, in the sense in which reasoning is a part, not the whole, of inference); and (5) testing the hypothesis by overt or imaginative action.

However, it is also important for teachers to have a clear idea of the purpose of students' critical thinking assessment. The reason was a variety of possible purposes exist, but no test or assessment procedure fits them all. For this matter," mentioned some major possible purposes, accompanied by comments as followed: (1) Diagnosing the levels of students' critical thinking. If we are to know where to focus our instruction, we must start with where they are in specific aspects of critical thinking. Tests can be helpful in this respect by showing specific areas of strength and weakness, (2) Giving students feedback about their critical thinking prowess. If students know their specific strengths and weaknesses, their attempts to improve can be better focused, (3) Motivating students to be better at critical thinking. Though frequently misused as a motivational device, tests can and do motivate students to learn the material they expect to be covered on the test, (4) Informing teachers about the success of their efforts to teach students to think critically. Teachers can use tests to obtain feedback about their instruction in critical thinking, (5) Doing research about critical thinking instructional questions and issues. Without careful comparison of a variety of approaches, the difficult issues in critical thinking instruction and curriculum organization cannot be answered, (6) Providing help in deciding whether a student should enter an educational program. People in some fields already use assessed critical thinking prowess to help make admissions decisions. Examples are medicine, nursing, law, and graduate school in general. Yet, the efficacy of existing efforts in selecting better critical thinkers has not been established. Research needs to be done in this area, and (7) Providing information for holding schools accountable for the critical thinking prowess of their students. A currently popular purpose for testing, including critical thinking testing, is to pressure schools and teachers to "measure up" by holding them accountable for the test results of their students.
The connection between critical thinking and music learning are the focus period which is needed in listening the music, the mental and emotion that are move while listening to the music. It triggers the mind to reach the relieve feeling when listening to and getting the sad soft feeling from the music. Sloboda separated study of music into two categories, namely musical enculturation and generative skills. Hallam and Lamont further explained that the study of enculturation is related to general development processes, namely the functions of the auditory system, innate musical abilities, which are very complex and different from each other. The kinds of musical learning subsumed under enculturation are best studied by using techniques and methods that do not require technical expertise, such as listening, rather than more specialized activities such as composing or performing. However, generative skills learn things that are more specific in music, such as performance, improvisation and composition. One strand of research has been focused on the role of practice in learning to play a musical instrument. ${ }^{14}$

\section{MATERIALS AND METHODS}

\section{Mind mapping}

Mind mapping technique was developed toward the end of the 1960s and has been employed in many different areas since the development. ${ }^{15}$ As a note taking technique, the mind map allows individuals to "organize facts and thoughts" in a map format containing a "central image, main themes radiating from the central image, branches with key images and key words, plus branches forming a connected nodal structure" ${ }^{16}$ In addition, the mind map helps students to assimilate new information, to think and to develop their conceptual schema. ${ }^{17}$ With the mind map of the thinking process becoming visible, the flow of thinking can be clearly described, both direction and branches of thought patterns. In the mind map picture, there is a big picture of a topic, as well as detailed information that complements understanding, easy to manage information effectively and systematically, improve memory, creativity, and innovation, because there is freedom to create and innovate in making and developing mind maps. The preliminary stages of making a mind map are as follows: (1) find keywords, (2) remove non-key words, (3) categorization (of existing keywords), and (4) specify hierarchy, which is systematic ordering of information.

In classroom learning, in general, students initially make linear notes of the lecturer explanations and results of discussions with their classmates. Linearly making notes is very popular and the most liked activity by everyone because it is easy to make and requires less effort to sort and create specific and detailed filters to the things 
being written. However, there are actually weaknesses in this model. In addition to being monotonous and unattractive (due to the lacks of color and images), linear notes are difficult to understand because of the abstract interrelationships between concepts, and keywords that are mixed with non-key words.

Center is the title, theme, or basic idea of a topic, generally placed in the middle of the mind map (this is not a standard rule, but flexible according to student creativity). The center is divided from the information grouping into categories and sub-categories based on hierarchies that have been determined in the previous stage. After the center, category, and hierarchy are formed, the next step is to find whether there is a relationship/correlation between categories and sub categories. There are several stages in making mind maps in groups, in learning violin practices. These stages are adjusted to the critical thinking skills of each group. These stages in MMBL (Mind Map Based Learning) are as in Table 1 below.

\section{Blended learning}

Some expert agree that Blended Learning is the combination between e-Leaning and face to face interaction in the class. The difference is in the composition of both of them. It was not in education field which was firstly used, but in the business field. ${ }^{18}$ The, it was used in higher education, then it was appeared in teaching and learning in the next year. ${ }^{19}$ It can be defined that blended learning is a mixture of two different types of meeting which are face to face meeting and online activities. Online activities can be delivered through asynchronous and synchronous meeting. It is claimed that using blended learning can improve pedagogy; increase access or flexibility; and increase cost effectiveness ${ }^{20}$ and Graham et al. ${ }^{21-22}$ In addition, there is growing needs for applying Blended Learning in teaching and the learning needs from students, thus the Blended Learning in this subject is categorized as open subject that can be taken by students anywhere and anytime. There were materials which were designed which matched with students lacks, wants, needs, procedure, input and so on. Everything was designed to improve their knowledge in violin musical instrument.

\section{RESULTS}

In a subject learning of violin musical instrument practice, there are several obstacles in the learning process. Students cannot master a musical work optimally and comprehensively. Based on the early observations, the problems were some students cannot remember the basic techniques which they have to master, do not have a shadow of the song as a whole, or cannot understand the background of a song. From the collegial discussion, literature review, and interview from students, thus mind map was the solution in this study. The data was taken from 2013 to last semester 2018, every year in one class consists of five students. There were 3 classes each year. Some students had repertoire songs based on the level of violin playing skills. Thus, each group collaborates to make a complete, comprehensive mind map, and details related to the songs which they will master. In five years, there are 75 students who were involved actively. The early data was gathered from the questionnaire of needs analysis, and the data was analyzed, then the draft of the material was designed which mind map was there as the key activities. The drafted material was evaluated by the experts of e-learning and content as the design of this subject is blended learning. After getting the final draft, it was ready to do the action for 5 semesters.

This subject is a compulsory subject that must be taken by first year ST. It consists of at least 16 meetings in one semester. The 16 meetings were divided into two modes of meeting; e-Learning and face to face interaction in the classroom. The composition of the blended learning is $50 \%$

\begin{tabular}{lllll} 
Table 1: Step by Step MMBL & & & \\
\hline Stage & Center & Category & Hierarchy & \\
\hline 1 & & & \\
2 & & & \\
3 & & & \\
4 & & & \\
5 & & & \\
6 & & & \\
7 & & & \\
8 & & & \\
\hline
\end{tabular}

\section{Table 2: Composition of blended learning of General English in one semester}

\begin{tabular}{llll} 
Mode of study & Face to face interaction in the classroom & e-learning (controlled practice) & e-learning (Online Discussion Forum) \\
Time allocation & 100 minutes per meeting in a week & 100 minutes per meeting in a week & 3 days in a week \\
Frequency & 8 times (including test) & 3 times & 3 times \\
\hline
\end{tabular}


for face to face in the classroom and 50\% for e-Learning. It can be seen in Table 2 .

The Online Discussion Forum (ODF) had been conducted 100 minutes in a meeting. It was a halfcontrolled activity in the form of theme-based discussion. The topics were matched with the material and tasks that they had in the e-Learning which provide controlled-practice. Before moving to e-Learning, students had learnt their new material, tasks, discussion and peer editing activities in face to face interaction meeting. They also got feedback not only from peer activities but also from the lecturer so that they have deep comprehension and full information that they need to do in the following e-learning class. Next, independent study plays as a reinforcement in this cycle as they need sometimes to push the knowledge to the long-term memory. Moreover, they got a flexible way to practice the English skills in their pace of study. Last, the cycle ends up in follow up phase in the form of review or assessment to check their knowledge and see if there is any problem while learning process in the e-learning ${ }^{6}$. Both lecturer and the student teachers need to follow the rules and follow the protocols before enrolling to the e-Learning class. It captures users' activities from logging in to logging out this course. The week meeting was open with introduction and greetings, then followed by the main focus that students need to do. They did mind mapping through ODF. The features of ODF are topics, started by, number of posting, reply numbers, editing tracking, personal message, and word count. The template of the mind mapping can be downloaded from the given icon in the meeting. Students followed the instructions inside the ODF once they click it. One of the topics from the ODF is to discuss the context of a song. They practice how to see the context. An example was given for them as a guide before in the face to face interaction or in the class and in the e-learning itself.

In the classroom or face to face interaction, there were steps that students need to follow before doing mind map. Initially, review of previous material was given as an opening activity. The purpose was to recall their memories, and build the knowledge of the new material by connecting them with their prior knowledge. It was hope that students got a helping hand in discussing the topic and doing mind mapping with their friends. Then, when it came to the mind mapping the flow were much easier for all of them. In the mind mapping phases, they did the first phase, which was each group discusses the things needed to master and understand a song. The first phase is generally one or two meetings. In the first phase, each group has decided on a category for the mind map. Categories are determined based on strong reasons for the main things needed in mastering songs. In general, the categories consist of work background, analysis of work, relevant etude, technique (scale and techniques in violin instrument, such as legato, pizzicato, staccato, and etc.), and musical expression (dynamic, tempo, cantabile, fuoco, etc.).If a category has been set, the group can continue to the next phase. The next phase is hierarchy, as follows: the background of the work consists of composer background, the era of the song was made (era/period), related to the style of play, the story behind song making, analysis of the work consists of the structure, shape and texture of the song, etude and technique relevant to the song.

Etude is a repertoire needed to strengthen the specific technique of a song; therefore, students determine etude after analyzing the work. The things that must be understood in the analysis of the work are structure, shape, song texture, and background of musical work. After getting a shadow and understanding through work analysis, students must be able to analyze difficult parts technically, and decide what ethics will be used to overcome the difficulties of the technique. For example, in the Sonata Mozart Kochel 301, the important part that students must give attention are in measuring 2226. Because in that period there are contrast dynamic and double-stops technique. The contrast of the dynamic in the measures comes from pianossisimo (very soft) suddenly turns into a forte (very hard), like the following piece of song. Another part that must be considered is the use of a double-stops technique. The double-stops is one of the techniques in the violin, such as reading two notes together and crossing strings to doublestops[23]. Following the song piece in the Sonata using double-stops techniques. As it has a double-stops technique, which can help students focus on practicing double-stops techniques, so that later the song can be played with a good double-stops and a good intonation. Besides etude, other things that need to consider are basic techniques, such as scale, legato, and so on. All these things affect the interpretation of playing songs. Mind mapping is very useful for overcoming problems in learning the violin practice. To unravel and map clearly the things needed in understanding a song as a whole, to get an appropriate interpretation of the picture, in order to convey the song as well as possible. Related to the stages in the MMBL (Mind Map Based Learning) described earlier, there are eight stages in accordance with the abilities of each group of students. In the sense that groups of students who are active and have good critical thinking can immediately jump at the top stage. Where the upper level MMBL students are required to be more active, independent, and critical, compared to the levels below. This is directly proportional to the diminishing dominance of lecturers as the MMBL level becomes higher. 
The first stage of MIMBL

In its application to the violin practice class, described as follows. At the first stage of MMBL, center is a song that has been determined by the lecturer. The lecturer also determines the categories. In this case, the categories are related to the things needed to be able to understand the song, including scale, expression, etude, song background and so forth. In addition to categories, lecturers have to also prepare hierarchies or sub-categories. For example, for the etude category, several numbers from different etude can be chosen, according to the students' need for song mastery. At stage one it is still the lecturer who determines the numbers and titles of the etude, this is included in the keywords, and determines if there is a correlation between hierarchies and categories.

The second stage of MIMBL

In stage two, the mind mapping picture is actually the same as stage one. The difference is that in stage one the lecturer has completed mind mapping with the lines of correlations, in stage two students are involved to look for correlations between hierarchies. The example for the predetermined category is Etude, which consists of several different Etude numbers and titles. From the different numbers and titles, discussing different violin technical skills, and at the same time it is very possible to have the same discussion. For example, in Etude by Enrico Polo no 1, the focus of the skill to be formed is the Double-stops technique, as it can be seen in the next piece of notation in Figure 1.

Etude Polo has a different concentration with etude Kayser no. 13, which is displayed in Figure 2.

In Etude Mazas no. 13, skills that want to be trained more to the difference between staccato and legato, as well as attention to the accent mark on certain parts. Although the two Etude numbers have different focus, there are important things to note in the two numbers, namely intonation. Intonation becomes vital in playing double-stops on Polo no. 1, so it is equally important to be able to play the notes on Etude Kayser no. 13 with good intonation. Then, a correlation line can be drawn that connects the hierarchy in Polo no. 1 and hierarchy in Kayser no. 13. Critical thinking at the basic stage can already be developed at this second stage of MMBL if students can analyze and find correlation relationships between hierarchies.

The third, fourth, and fitfh stage of MIMBL

In MMBL stages three, four, and five students are involved in filling in keywords. The difference in the three stages is that in stages three and four there is a process of discussion between lecturers and students, in stage three the dominance of lecturers, stage four lecturers provide more space for students to explore, whereas in stage five lecturers only pay attention from the outside and direct as necessary. The following picture is a picture of mind mapping stage three; the lecturer gives students the opportunity to be involved in determining keywords and correlations. Example of mind mapping stage three in Figure 3 below.

Following is a description of mind mapping in stage five, where the lecturer has prepared branches for hierarchy. However, students are looking for relevant and appropriate key words to fill in these hierarchies. It can be seen in Figure 4 below.

The application of keywords to fill in the hierarchies of violin learning is as follows, as an example, one of the categories determined by the lecturer to understand the song (center), which must be an analysis of the

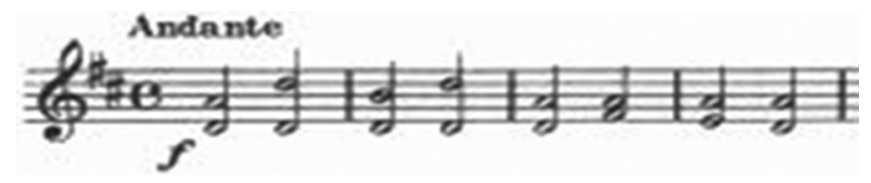

Figure 1: Etude Polo No. 1

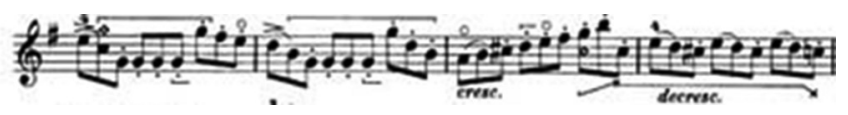

Figure 2: Etude Kayser No. 13

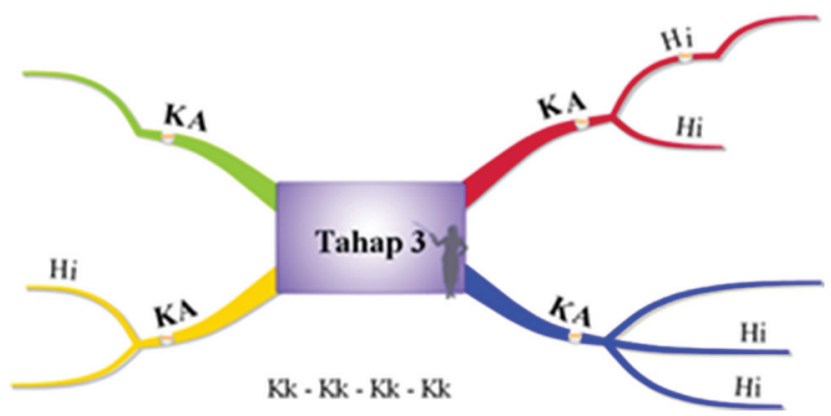

Figure 3: Example of stage 3 mind map

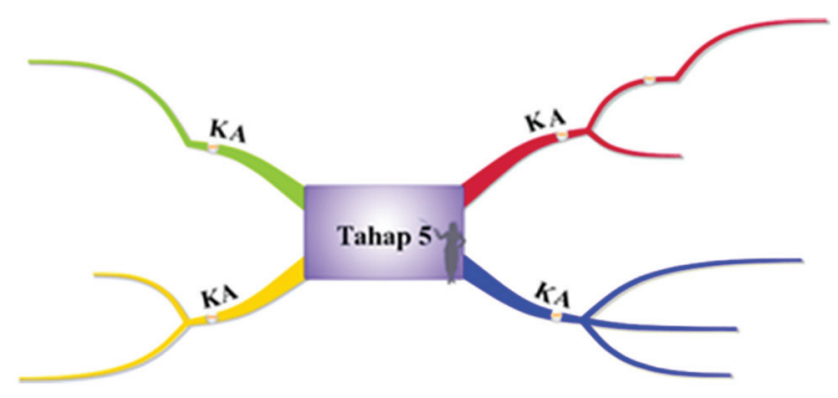

Figure 4: Example of stage 5 mind map 
song (category). And the lecturer has made branches of five hierarchies, students are invited to try to fill in the keywords in each hierarchy. Groups that still cannot understand the song analysis can be placed in the third stage of MMBL, where the lecturer assists intensively. For more independent groups, level four can be directly applied, students continue to discuss with students with dominance on students. For groups that are active, and quite critical are placed at level five, lecturers only pay attention to the key words proposed by students. If the song analysis category, so the hierarchies or analysis that must be done on the song include analysis of melody, harmony, song form, tempo, and expression. These hierarchies can be continuing into new branches (sub hierarchies). For example, in the expression hierarchy, dynamics, phrases, articulations, and so on can be made.

The sixth and seventh stage of MIMBL

Determination of the number and content of hierarchy, and correlation based on student discussions accompanied by references to reading sources.

It can be seen in Figure 5 that the example of the seventh stage of image above looks similar to the description of the sixth MMBL stage, namely the center and the number of branch categories determined by the lecturer. However, if at stage six keywords for a category are given by the lecturer, students are given space to discuss to determine

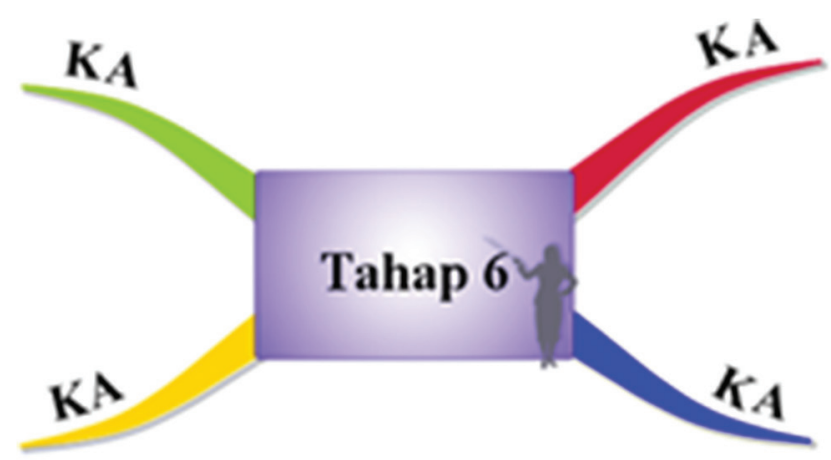

Figure 5: Example of stage 7 mind map

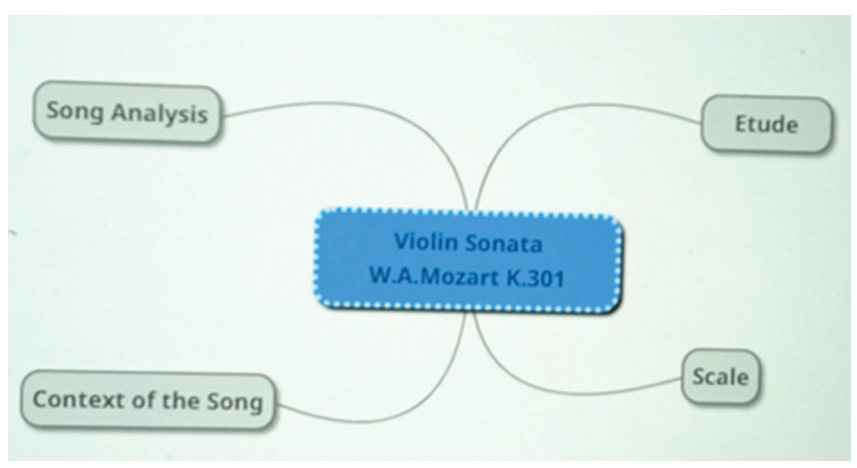

Figure 6: Example center categories the keywords in each category at stage seven. It can be seen in Figure 6 below.

The category in Figure 6 illustrates the categories of the song Mozart Violin Sonata by WA Mozart Kochel 301. In the sense of understanding and playing the song Violin Sonata by WA Mozart Kochel 301, must master Etude and Scale, perform song analysis, and seek information from various sources regarding the context of the song. When was the song made, in what era of music, what composers thought, and everything related to the song Violin Sonata by W. A. Mozart Kochel 301.

\section{The eighth stage of MIMBL}

Stage eight is the final stage that requires students to think critically and independently. The lecturer only gives advice on the choice of song (only center), the rest of the students are directed to determine the number of category branches, hierarchies, key words and correlations. For example, the center song Violin Sonata by W. A. Mozart Kochel 301, students must discuss with their group friends what are the things needed to master the song. This stage it is very open for students to explore ideas, it is very possible that there are different patterns and forms of mind mapping in different groups. In the application for several years in violin practice class, mind mapping is formed from the center of a song, in general the categories consist of etude, scale, song analysis, and context of the song. However, the categories can be in different order for different groups. All processes of mind mapping were calculated and classified, then analyzed. The result in the process of mind mapping can be seen in the Table 3 below.

There was similar trend for the first phase and the second one in 1 semester. It stayed in around 5 or 6 students who participated. In the next phases 3 and 4 , the numbers raise steadily, but there was significant raising from 6 to 9 . Then, it was followed by 13 in the phase 5 . In this phase, students had more confidence to share and get involved in the any topics. It can be said that more than half students were active. The last three phases the improving quantity was also followed by the quality of the thinking as they were able to meet whole phase in

\begin{tabular}{lc} 
Table 3: Mind mapping results in $\mathbf{1}$ year in $\mathbf{2 0 1 3}$ \\
\hline MMBL & Quantity of participation \\
\hline Phase 1 & 5 \\
Phase 2 & 6 \\
Phase 3 & 9 \\
Phase 4 & 11 \\
Phase 5 & 13 \\
Phase 6 & 14 \\
Phase 7 & 14 \\
Phase 8 & 15 \\
\hline
\end{tabular}




\section{Table 4: The result for 5 years}

\section{MMBL}

\section{Phase 1}

Phase 2

Phase 3

Phase 4

Phase 5

Phase 6

Phase 7

Phase 8

mind mapping. Phase 6 and phase 7 are 14 and the last one was 15.The result of the MMBL for 5 years can be seen in the Table 4.

The table shows the score for five years in doing the mind mapping. The number was gathered from the calculation of those who participated in mind mapping discussion. The improvement was happened as get familiar with the mind. As they reached the goals means they are categorized as critical thinker. They showed not only their cognitive skills but also their thinking order, which also means the ability to have critical thinking in music. The design of teaching learning process promotes the situation which triggers their initiatives, ideas and creativities. The nature of among approach by Ki Hajar Dewantara that learning should provide the students with humanity feeling and context. It prompted them to get involved in any comfortable situation thus they would end up in friendly discussion. Thus, critical thinking can be fulfilled if students are given these situations above. Students are no longer passive participants who take everything are given in the class, e-learning class and daily life, without questioning the ideas. They start questioning, judging, evaluating information and creating something useful.

\section{CONCLUSION}

Differences in order are formed due to considerations of more important things that are owned, controlled, or done. There is a group of students who think that mastering skills technically is the most crucial thing to have, so the most important category for this group is related to scale and etude. In this group, there are more branches in the hierarchy than those related to song analysis and background work. There are also groups who argue that the most important thing is understanding textual songs, such as details of the song. What most important is that each student must understand the reasons behind the selection of categories and hierarchy in the mind map.

\section{ACKNOWLEDGEMENT}

The authors would like to thank all reviewers and volunteers to make this study done. Authors also gratefully acknowledge Brain Science and Engineering Innovation Research Group, Mae Fah Luang University grant (2019) (MFU-grant no. 611U109005) and 2020, Thailand for the support.

\section{REFERENCES}

1. Singer W. Development and Plasticity of Cortical Processing Architectures.Science.1995; 270: 5237.

2. Squire LR and Kandel ER. Memory: From Mind to Molecules. New York, NY: Scientific American Library, 2009.

3. Hinton C, Kurt W Fischer and Catherine Glennon. 2012. Mind, Brain and Education. NME Foundation: New England.

4. Dewantara $\mathrm{KH}$ and Karya $\mathrm{KH}$. Dewantara bagian pertama: Pendidikan. Yogyakarta: Majelis Luhur Persatuan Tamansiswa, 1977.

5. Floriasti TW. Developing character building through multicultural reading text. Conference proceedings. 2012: 456-464.

6. Floriasti TW. Online discussion forum untuk mengkonstruksi pengetahuan dan interaksi berdasarkan nilai pancasila bekerjasama dan menghargai (280-292). Book chapter in Pancasila dalam Praksis Pendidikan. UNY Press, 2018.

7. Field ST. Critical thinking skills and the secondary school choral music classroom. Unpublished doctoral dissertation. Teachers College, Columbia University, 1977.

8. Mertes L. Thinking and writing. Middle School Journal 1991; 22:24-25.

9. Ennis $\mathrm{RH}$. Critical thinking assessment. Theory into practice 1993; 32(3): 179-186.

10. Huitt W. Critical thinking: An overview. Educational Psychology Interactive. Valdosta, GA: Valdosta State University, 1998.

11. Pogonowski L. Developing skills in critical thinking and problem solving. Music Educators Journal. 1987; 73(6): 37-41.

12. Garrison DR. Critical thinking and adult education: A conceptual model for developing critical thinking in adult learners. International Journal of Lifelong Education. 1991; 10(4): 287-303.

13. Dewey J. How we Think, Boston, D.C. Heath, 1983

14. Ericsson KA. Deliberate practice and the acquisition of expert performance. In: H. Jorgensen \& A. Lehman (Eds.), Does practice make perfect? Current theory and research on instrumental music practice, NMH-publikasjoner 1997:1, Oslo, Norway: Norges Musikhogskule 1997.

15. Evrekli E, lel D and Balim A. Development of a scoring system to assess mind maps. Procedia Social and Behavioral Sciences 2010; 2: 2330-2334.

16. Tee TK, Azman MNA, Mohamed S, Muhammad M, Mohamad MM, Md Yunos J. Buzan Mind Mapping: An Efficient Technique for Note-Taking. World Academy of Science, Engineering and Technology International Journal of Social, Human Science and Engineering 2014; 8(1): 20-24.

17. Keles O. Elementary Teacher' Views on Mind Mapping. International Journal of Education 2012; 4(1): 93-100.

18. Sharma P and Barrett B. Blended Learning. Oxford: Macmillan, 2007.

19. MacDonald J. Blended Learning and Online Tutoring. Aldershot Hampshire: Gower, 2016. 
20. Graham C. Blended Learning Systems: Definition, Current Trends, and Future Directions. [Online] 2014 [Cited 2017 June 12] Available from URL http://www.publicationshare.com.

21. Stracke E. A road to understand: A qualitative study into by learners drop out of a blended language learning (BLL) environment. ReCALL. 2017; 19(1): 57-58.
22. Tomlinson B and Whittaker C. Blended Learning in English Language Teaching: Course Design and Implementation. London: British Council, 2013.

23. Harvey C. Double Stop Beginnings for the Violin, Book One. Philadelphia: C. Harvey Publications 2014.

\section{Authors Contribution:}

YJF- Concept and design of the study, statistically analyzed and interpreted, manuscript preparation, critical revision of the manuscript; TWF- Statistically analyzed and interpreted, manuscript preparation, critical revision of the manuscript, critical revision of the manuscript; D- Statistically analyzed and interpreted, manuscript preparation, critical revision of the manuscript, critical revision of the manuscript; PS- Manuscript preparation, critical revision of the manuscript.

Work attributed to:

Department of Music Education, Yogyakarta State University, Yogyakarta, Indonesia.

Department of English Education, Yogyakarta State University, Yogyakarta, Indonesia.

Graduate School of the Indonesia Institute of the Arts Yogyakarta, Yogyakarta, Indonesia.

Brain Science and Engineering Innovation Research Group, School of Anti-Aging and Regenerative Medicine, Mae Fah Luang University, Thailand.

Orcid ID:

Yunike Juniarti Fitria - (D) https://orcid.org/0000-0002-9492-6503

Tri Wahyuni Floriasti - (1) https://orcid.org/0000-0003-3474-414X

Dr. Djohan - io https://orcid.org/0000-0002-6705-3436

Dr. Phakkharawat Sittiprapaporn - (iD https://orcid.org/0000-0002-4103-9396

Source of Support: Brain Science and Engineering Innovation Research Group, Mae Fah Luang University grant (2019) (MFU-grant no. 611U109005) and 2020, Thailand, Conflict of Interest: None. 